\title{
Nectin-2 and Nectin-4 Adhesion Molecules in Patients with Breast Cancer
}

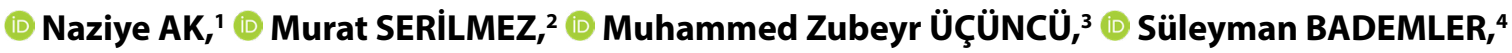 \\ DSEZai VATANSEVER'
}

\begin{abstract}
'Department of Medical Oncology, Istanbul University Institute of Oncology, Istanbul-Turkey ${ }^{2}$ Department of Biochemistry, Istanbul University Institute of Oncology, Istanbul-Turkey ${ }^{3}$ Department of General Surgery, Gelişim University Faculty of Health Sciences, Istanbul-Turkey

${ }^{4}$ Department of General Surgery, Istanbul University Institute of Oncology, Istanbul-Turkey
\end{abstract}

\begin{abstract}
OBJECTIVE
Evaluation of the nectin-2 and nectin-4 protein and mRNA expression levels is aimed in this study, with concerning diagnostic and predictive value in breast cancer patients.

\section{METHODS}

Sixty patients with pathologically and radiologically verified breast cancer who were treated at the Istanbul University, Institute of Oncology, between 2017 and 2018 are included in the study. Circulating nectin- 2 and nectin- 4 protein levels were evaluated by solid-phase enzyme-linked immunosorbent assay (Abbkine Scientific Co., Ltd.). For analyzing nectin-2- and nectin-4-specific mRNA in sera of the patients, circulating cell-free RNA was extracted from serum using a monophasic phenol and guanidine thiocyanate solution (Roche, Mannheim, Germany), according to the manufacturer's protocol.
\end{abstract}

\section{RESULTS}

The median age of patients was 53 years. The mean tumor size was $30.21 \pm 17.32 \mathrm{~mm}$. Forty-one patients were in the luminal group. Lymph node involvement was detected in 25 patients. The nectin- 4 expression level was statistically significantly higher in those with Ki-67 $\geq 30$ and those with positive distant metastasis compared to the other group. In addition, nectin-2 expression was higher in patients with Grade 3 tumors.

\section{CONCLUSION}

High levels of nectin-2 and nectin-4 expression in the serum of patients correlate with poor disease characteristics of breast cancer.

Keywords: Adhesion molecules; breast cancer; histology; nectin; pathology.

Copyright $\odot$ 2021, Turkish Society for Radiation Oncology

\section{Introduction}

Breast cancer comes first as the cancer-related cause of death in the female population; despite the effective screening programs which result in early diagnosis. The survival rate is high when the disease is diagnosed in the early stage; however, $20-30 \%$ of local breast cancer cases will be progressed to the metastatic stage. [1] The progressive potential of the disease is based on disease and patient characteristics such as age, receptor status, and tumoral invasiveness. Aggressive disease courses in patients with worse pathological 
characteristics underlines the demand for enhanced methods to predict the patients who are a candidate for aggressive and novel targeted strategies for treatment. Elevated plasma CA-15-3 levels are tested frequently for surveillance of recurrent breast cancer; however, its correlation with patient characteristics and prediction of treatment modalities are not validated and routine analysis does not recommend in current guidelines. [2] At present, the most commonly used markers to guide the treatment options are hormone receptor and HER2-neu status on pathological material. However, disease courses are different even in patients with the same histologic properties.[3] There is a need for discovering new biomarkers to explain these differences.

Serum biomarkers are extensively investigated in cancer patients to close the gaps in diagnostic and predictive markers. Nectins are a kind of immunoglobulin-like homo-heterophilic cell adhesion proteins that maintain intercellular adherence and tight junctions. [4] There are four nectin proteins that described; nectin-1 and -2 are mainly found in adult somatic tissues, nectin-3 is expressed mainly in reproductive organs such as testes and placenta, and also nectin- 4 expression is naturally limited to the placenta.[5-7] On the other hand, binding characteristics are different for each nectin subgroup.[6] There have been reports of expression of nectin- 4 in ductal breast carcinoma and lung adenocarcinomas.[8-10] Nectin-2 is less frequently studied in oncologic patients; Oshima et al.[11] have been shown the elevated expression in breast cancer tissues. However, in previous studies showing diagnostic biomarker potential of nectin-2 and nectin-4; the argument was not firmly made that nectin- 2 and -4 could be therapeutic targets, or predicting prognostic and clinical properties of the disease.[10,12] With this study, we aimed to define whether overexpression of nectin proteins and mRNA remnants in plasma correlates with related clinical properties of patients with breast cancer.

\section{Materials and Methods}

\section{Study Population and Design}

The study group included 60 breast cancer patients who were receiving treatment at the Istanbul University, Institute of Oncology, between 2017 and 2018. All patients were diagnosed pathologically or radiologically. The disease was staged by physician according to the American Joint Committee on Cancer staging system. All volunteers are informed and then signed consent form for the study and ethical approval was obtained from Istanbul Medical Faculty Ethical Committee.
Venous blood samples were obtained from patients before any treatment was given, then clotted for $10 \mathrm{~min}$ before centrifuged. The collected serum samples stored at $-20^{\circ} \mathrm{C}$ until analysis after the centrifugation $(10 \mathrm{~min}$ $4000 \mathrm{rpm}$ ) at the room temperature.

\section{Evaluation of Serum Nectin-2 and Nectin-4 Levels}

Serum nectin- 2 and nectin- 4 protein levels were determined by enzyme-linked immunosorbent assay (ELISA) method (Shanghai Sunred Biological Technology Co. Ltd.). Serum samples/standards, biotinylated Fab monoclonal capture antibody, and streptavidin horseradish peroxidase conjugates were, respectively, added to the wells which are pre-coated antibody. During the $1 \mathrm{~h}$ incubation at $37^{\circ} \mathrm{C}$, the antigen-antibody complexes formed. After this incubation, the unbound material was washed away and the colorless chromogen solution was added and again incubated at $37^{\circ} \mathrm{C}$ for 10 min (protect from light) for the conversion of the colorless solution to a blue solution. Since the enzyme interacts with its substrate, a color reaction occurred in direct proportion to the antigen concentration in the sample. This color reaction was stopped by the addition of an acidic stop solution and the blue color turned yellow. The colored reaction product was measured using an automated ELISA reader (ChroMate ${ }^{\oplus} 4300$ ) at $450 \mathrm{~nm}$. The concentrations of the samples were determined with the help of the standard curve drawn with standards of known concentration and the results were expressed as ng/L.

\section{Quantification of Nectin-2 and Nectin-4 mRNA Ex- pression in Serum}

Nectin-2- and nectin-4-specific mRNAs in serum samples of patients' total RNA were isolated using a monophasic phenol and guanidine thiocyanate solution. Two hundred microliters of sample, $800 \mu \mathrm{l}$ of RNA isolation solution, and $200 \mu$ chloroform are mixed. The mixture is incubated on ice for $5 \mathrm{~min}$ and centrifuged at $11,000 \mathrm{rpm}$ for $15 \mathrm{~min}$ at $4^{\circ} \mathrm{C}$. The RNA phase is transferred to a $550 \mu \mathrm{l}$ propanol-containing tube. After centrifugation at 11,000 rpm for $10 \mathrm{~min}$ at $4^{\circ} \mathrm{C}$, RNA is washed with $75 \%$ alcohol, dried at room temperature, and transfused in $20 \mu \mathrm{l}$ RNase-free water. cDNA synthesis was performed according to the procedure of a commercial kit (Roche, Mannheim, Germany). cDNA provides superior components that ensure total RNA templates. Nectin-2 and nectin-4 gene expression in serum were measured semi-quantitatively using GAPDH (housekeeping gen) and SYBR Green. Real-time polymerase chain reaction 
(RT-PCR) process was performed using LightCycler 480 Instrument. RT-PCR components and conditions which have been used are explained in Table 1a and 1b. Probe library was used in primer selection. The confirmation of the cycle product for each molecule was carried out with melting curve analysis. Instrument measurable threshold value of fluorescence level in RT-PCR reaction the cycle it passes is called Ct (cycle threshold). According to the $\mathrm{Ct}$ value obtained, $2-\Delta \Delta \mathrm{Ct}$ method is used.

\section{Statistical Analysis}

SPSS software was used for recording and analyzing the data (SPSS-21, Chicago, IL, USA). The Mann-Whitney U-test was applied by examining the conformity of variables to a normal distribution using visual and analytical methods (Kolmogorov-Smirnov/Shapiro-Wilk tests). $\mathrm{P}<0.05$ was accepted as statistically significant.

\section{Results}

The median age of the study population was 53 (range: 24-71) years. Twenty-eight patients were in the premenopausal period. The tumor was located on the right side in 27 patients. The mean tumor size was $30.21 \pm 17.32$ $\mathrm{mm}$. Tumor pathology in 44 patients was pathologically reported as invasive ductal carcinoma. The number of patients with Grade 3 was 32. De novo distant metastasis was detected in four patients. Forty-one patients were in the luminal group. Lymph node involvement was detected in 25 patients. The clinical and pathological characteristics of patients are summarized in Table 2.

When the menopausal status and tumor localization of the patients included in the study were compared, no significant difference was found between the nectin- 2 and nectin- 4 levels. When the pathological characteristics of the patients were compared, the patients who were showed poor prognostic disease characteristics such as larger tumor size, lymph node positivity, the presence of lymphovascular invasion, presence of necrosis, and histological Grade 3 have higher serum levels of nectin protein levels than the data showing good prognosis; however, statistically insignificant. The nectin-4 expression level was statistically significantly higher in those with Ki-67 $\geq 30$ and those with positive distant metastasis compared to the other group. In addition, nectin-2 expression was higher in patients with Grade 3 tumors which also found statistically significant. The results of nectin level measurements are shown in Table 3.
Table 1a. Real-Time PCR Components

\begin{tabular}{|c|c|c|}
\hline Component name & \multicolumn{2}{|c|}{ Sample volume } \\
\hline Qpcr GreenMaster & & $10 \mu \mathrm{l}$ \\
\hline Primer $\mathrm{F}$ & & $0.6 \mu l$ \\
\hline Primer $\mathrm{R}$ & & $0.6 \mu \mathrm{l}$ \\
\hline cDNA & & $3 \mu l$ \\
\hline $\mathrm{dH}_{2} \mathrm{O}$ & & $5.8 \mu \mathrm{l}$ \\
\hline Total & & $20 \mu \mathrm{l}$ \\
\hline \multicolumn{3}{|c|}{$\begin{array}{l}\text { PCR: Polymerase chain reaction; cDNA: Complementary DNA; } \mathrm{dH}_{2} \mathrm{O} \text { : Distilled } \\
\text { water }\end{array}$} \\
\hline \multicolumn{3}{|c|}{ Table 1b. Real-Time PCR Conditions } \\
\hline Condition & Temperature $\left({ }^{\circ} \mathrm{C}\right)$ & Time \\
\hline Polymerase Activation & 95 & 2 minutes \\
\hline Denaturation & 95 & 15 seconds \\
\hline Annealing 55 & 20 seconds & \\
\hline Extension 72 & 30 seconds & \\
\hline
\end{tabular}

Table 2 The clinical and pathological characteristics of patients

\begin{tabular}{|c|c|}
\hline Characteristics & n (\%) \\
\hline Median age (years) & 53 (Range: 24-71) \\
\hline \multicolumn{2}{|l|}{ Menapousal status } \\
\hline Premenapouse & $28(46.7)$ \\
\hline Postmenapouse & $32(53.3)$ \\
\hline Tumor size (mm) & $30.21 \pm 17.32$ \\
\hline \multicolumn{2}{|l|}{ Tumor localization } \\
\hline Right & $27(45)$ \\
\hline Left & $33(55)$ \\
\hline \multicolumn{2}{|l|}{ Histology } \\
\hline Invasive ductal ca & $44(73.3)$ \\
\hline Other & $16(26.7)$ \\
\hline \multicolumn{2}{|l|}{ Histological grade } \\
\hline Grades I-II & $28(46.7)$ \\
\hline Grade III & $32(53.3)$ \\
\hline \multicolumn{2}{|l|}{ Metastasis } \\
\hline Absent & $56(93.3)$ \\
\hline Present & $4(6.7)$ \\
\hline \multicolumn{2}{|l|}{ Nodal status } \\
\hline Positive & $25(41.6)$ \\
\hline Negative & $35(58.4)$ \\
\hline \multicolumn{2}{|l|}{ Molecular subtype } \\
\hline Luminal & $41(68.3)$ \\
\hline Non luminal & $19(31.7)$ \\
\hline
\end{tabular}

\section{Discussion}

In this study, increased serum mRNA expression of nectin-2 and nectin- 4 has been detected in patients with breast carcinoma which have pathological worse 
Table 3 Distribution of Nectin-2 and 4 levels

\begin{tabular}{|c|c|c|c|c|c|c|c|c|}
\hline & $\begin{array}{l}\text { Nectin-2 } \\
\text { protein }\end{array}$ & $\mathbf{p}$ & $\begin{array}{l}\text { Nectin-2 } \\
\text { expression }\end{array}$ & $\underset{\text { protein }}{\mathbf{p}}$ & Nectin-4 & $\mathbf{p}$ & $\begin{array}{c}\text { Nectin-4 } \\
\text { expression }\end{array}$ & $\mathbf{p}$ \\
\hline \multicolumn{9}{|l|}{ Menapousal status } \\
\hline Premenapouse & $12.96 \pm 14.90$ & 0.993 & $0.91 \pm 0.90$ & 0.770 & $11.29 \pm 14.13$ & 0.898 & $0.55 \pm 0.75$ & 0.380 \\
\hline Postmenapouse & $10.09 \pm 12.38$ & & $1.18 \pm 1.36$ & & $9.75 \pm 12.73$ & & $0.71 \pm 1.05$ & \\
\hline \multicolumn{9}{|l|}{ Localisation } \\
\hline Right & $14.18 \pm 15.12$ & 0.078 & $0.82 \pm 0.81$ & 0.521 & $10.75 \pm 13.65$ & 0.876 & $0.65 \pm 0.85$ & 0.627 \\
\hline Left & $9.25 \pm 12.04$ & & $1.24 \pm 1.36$ & & $10.33 \pm 13.31$ & & $0.60 \pm 0.96$ & \\
\hline \multicolumn{9}{|c|}{ Lymphovascular invasion } \\
\hline Yes & $11.65 \pm 13.55$ & 0.683 & $1.29 \pm 1.30$ & 0.446 & $11.94 \pm 14.33$ & 0.471 & $0.63 \pm 0.82$ & 0.860 \\
\hline No & $10.52 \pm 12.50$ & & $0.84 \pm 1.04$ & & $10.44 \pm 13.37$ & & $0.58 \pm 0.95$ & \\
\hline \multicolumn{9}{|l|}{ Necrosis } \\
\hline Yes & $14.26 \pm 14.71$ & 0.695 & $0.84 \pm 0.70$ & 0.811 & $15.31 \pm 15.73$ & 0.669 & $0.69 \pm 0.88$ & 0.759 \\
\hline No & $9.05 \pm 10.67$ & & $1.17 \pm 1.24$ & & $7.51 \pm 10.44$ & & $0.09 \pm 0.07$ & \\
\hline \multicolumn{9}{|l|}{ Tumor size } \\
\hline$<2 \mathrm{~cm}$ & $9.39 \pm 11.02$ & 0.597 & $0.57 \pm 0.38$ & 0.220 & $7.32 \pm 10.51$ & 0.605 & $0.57 \pm 0.85$ & 0.619 \\
\hline$>2 \mathrm{~cm}$ & $12.24 \pm 14.46$ & & $1.20 \pm 1.28$ & & $11.60 \pm 14.12$ & & $0.78 \pm 1.08$ & \\
\hline \multicolumn{9}{|l|}{ Metastasis } \\
\hline Yes & $12.19 \pm 13.99$ & 0.099 & $1.09 \pm 1.18$ & 0.372 & $11.15 \pm 13.70$ & 0.272 & $0.67 \pm 0.92$ & 0.046 \\
\hline No & $3.61 \pm 1.60$ & & $0.44 \pm 0.16$ & & $2.98 \pm 1.35$ & & $0.08 \pm 0.09$ & \\
\hline \multicolumn{9}{|l|}{ Molecular subtype } \\
\hline Luminal & $13.49 \pm 14.68$ & 0.113 & $1.04 \pm 1.15$ & 0.565 & $12.39 \pm 14.41$ & 0.219 & $0.70 \pm 0.97$ & 0.526 \\
\hline Non luminal & $7.11 \pm 9.96$ & & $1.05 \pm 1.19$ & & $6.32 \pm 9.67$ & & $0.46 \pm 0.71$ & \\
\hline \multicolumn{9}{|l|}{ Pathology } \\
\hline Invasive Ductal & $8.90 \pm 10.35$ & 0.165 & $0.85 \pm 1.00$ & 0.074 & $9.10 \pm 11.80$ & 0.324 & $0.65 \pm 0.98$ & 0.192 \\
\hline Other & $20.28 \pm 19.34$ & & $1.70 \pm 1.41$ & & $15.27 \pm 17.31$ & & $0.53 \pm 0.61$ & \\
\hline \multicolumn{9}{|l|}{ Grade } \\
\hline 1 and 2 & $9.47 \pm 11.94$ & 0.053 & $0.90 \pm 1.06$ & 0.047 & $8.34 \pm 11.35$ & 0.063 & $0.60 \pm 0.99$ & 0.217 \\
\hline 3 & $14.81 \pm 15.72$ & & $1.27 \pm 1.28$ & & $13.98 \pm 15.65$ & & $0.69 \pm 0.80$ & \\
\hline \multicolumn{9}{|l|}{ Ki67 } \\
\hline$\geq 30$ & $14.53 \pm 15.86$ & 0.139 & $1.07 \pm 1.23$ & 0.831 & $13.80 \pm 15.38$ & 0.109 & $0.82 \pm 0.93$ & 0.019 \\
\hline$<30$ & $8.35 \pm 10.49$ & & $1.00 \pm 1.07$ & & $7.22 \pm 10.61$ & & $0.29 \pm 0.31$ & \\
\hline \multicolumn{9}{|l|}{ Lenf node status } \\
\hline Positive & $14.20 \pm 15.79$ & 0.212 & $1.07 \pm 1.09$ & 0.895 & $12.55 \pm 15.19$ & 0.336 & $0.59 \pm 0.86$ & 0.822 \\
\hline Negative & $9.41 \pm 11.51$ & & $1.02 \pm 1.21$ & & $8.92 \pm 11.70$ & & $0.65 \pm 0.95$ & \\
\hline
\end{tabular}

characteristics. Nectin-2 mRNA expression level is elevated in Grade 3 tumors. Nectin-4 mRNA expression level is elevated in metastatic patients and patients with high pathological Ki-67 levels. However, we could not able to show any statistically significant difference between serum protein levels and clinicopathologic properties of the disease. Using nectin- 4 for the active follow-up of breast cancer patients might help to early detection of metastatic patients. Until now, there is no established biomarker to use for active follow-up of breast cancer patients. Current guidelines do not recommend ordering serum analysis of any biomarker even for CA-15-3. This study could be a starting point to research the usefulness of nectin molecules as a biomarker for breast cancer surveillance.
The loss of function of tight connections that control cell-cell adhesion and intracellular permeability causes the spread of cancer cells and metastasis. Nectins, which are calcium-independent immunoglobulin-like cell adhesion molecules, are in a relationship with cadherin in various intercellular associations, sometimes independently, and sometimes in cooperation with the afadine molecule. $[13,14]$ All nectin molecules except nectin-4 are normally expressed in adult epithelial, endothelial, hematopoietic, and neuronal tissues. Although nectin- 4 is expressed during embryogenesis, not detectable in adult tissues or serum.[15] Nectin-2mediated cell adhesion has been implicated in the formation of cadherin-induced adherence complexes and the formation of a claudin bound tight linkage complex 
in epithelial cells. Overexpression of nectins is related to cancer and there is evidence that tight links are necessary to cell growth regulation.

Overexpression of nectin- 2 and nectin- 4 in cancerous cells has been detected and has been found associated with poor prognosis in previous reports. Nectin-2 is a less frequently studied subgroup of the nectins in cancer patients. Diagnostic and prognostic value of nectin-2 in colorectal cancer,[16] pancreatic cancer,[17] gallbladder carcinoma,[18] esophageal cancer,[19] and lung cancer[20] has been studied earlier. Until now, only Oshima et al.[11] evaluated nectin-2 on ovarian cancer and breast cancer tissues pathologically using gene expression profile analysis and immunohistochemistry. They also evaluated various in vitro cancer cell cultures and found elevated levels of nectin-2. They hypothesized nectin- 2 might be a treatment target since anti-nectin-2 antibodies have resulted in antigen-dependent cell death.[11] However, ensuing studies have not evolved in this era. In our study, nectin-2 is evaluated in serum and found to be related to Grade 3 tumors. Although this study requires validation, nectin-2 might be evaluated for prognostic and treatment predictive biomarker in further researches based on this pilot study. There is evidence that nectin-2 may serve as new immunogenic therapies. T-cell immunoglobulin and ITIM domain (TIGIT) recognize nectin-like adhesion molecules, specifically nectin-2, and therefore play a critical role in the innate immune response to malignant transformation.[21]

High expression of nectin- 4 in ductal breast, lung, and pancreatic cancers and its relation with a poor prognosis has been shown. $[9,22]$ Moreover, according to another study with ovarian carcinoma patients, the expression of nectin- 4 could be related to resistance to chemotherapeutic agents. [23] Lattanzio et al.[22] studied nectin- 4 expression in their cohort of node-negative early breast cancer. The presence of nectin- 4 on cell membrane of tumor cells was associated with poor metastasis-free survival in patients with luminal-A tumors. The high serum level of nectin- 4 in metastatic patients in our study suggests that it can be used as a serum marker to detect early metastasis in patients by contributing to this study. In addition, we have found that the patients with higher Ki-67 level show high nectin-4 level that also correlates with the metastatic predisposition of the tumor.

There are several limitations to this study that must be mentioned. First of all, this is a cross-sectional study that the survival results of the patients were not noted. Furthermore, there is not a normal control group, and the study cohort is categorized by medians of the patients' nectin-2 and nectin- 4 serum levels. On the other hand, the main strength of the study is the comprehensive evaluation of serum nectin- 2 and nectin- 4 levels with two different methods; RT-PCR and ELISA. Furthermore, although tissue studies are available in the literature with this biomarker, synchronous serum analyses of these two markers in breast cancer are rare.

\section{Conclusion}

Nectin-4 mRNA is overexpressed in the patients with high Ki-67 levels and metastasis. Furthermore, nectin-2 mRNA is higher in the serum of patients with Grade 3 tumors. Further studies are recommended to determine the impact of nectin- 2 and nectin- 4 as a surveillance marker. Studies that are designed prospectively which contain serial measurement of serum levels of these biomarkers might give appropriate results to change the practice.

Peer-review: Externally peer-reviewed.

Conflict of Interest: The authors declare that they have no conflict of interest.

Ethics Committee Approval: The study was approved by the Istanbul Medical Faculty Clinical Research Ethics Committee (No: 18, Date: 28/10/2016).

Financial Support: The study is funded by the Scientific Research Projects Unit of Istanbul University with project number of 24545 .

Authorship contributions: Concept - S.B., S.V.; Design - S.B., S.V., M.S.; Supervision - S.B., S.V., M.Z.Ü; Materials - M.S., S.B., S.V.; Data collection and/or processing - N.A., M.Z.Ü.; Data analysis and/or interpretation - N.A., M.Z.Ü.; Literature search - N.A., M.S., S.B.; Writing - N.A., S.B., S.V., M.S.; Critical review - N.A., M.S., M.Z.Ü., S.B., S.V.

\section{References}

1. Early Breast Cancer Trialists' Collaborative Group (EBCTCG). Effects of chemotherapy and hormonal therapy for early breast cancer on recurrence and 15year survival: an overview of the randomised trials. Lancet 2005;365(9472):1687-717.

2. Park YH, Senkus-Konefka E, Im SA, Pentheroudakis G, Saji S, Gupta S, et al. Pan-Asian adapted ESMO clinical practice guidelines for the management of patients with early breast cancer: A KSMO-ESMO initiative endorsed by CSCO, ISMPO, JSMO, MOS, SSO and TOS. Ann Oncol 2020;31(4):451-69.

3. Makki J. Diversity of breast carcinoma: histological 
subtypes and clinical relevance. Clin Med Insights Pathol 2015;8:23-31.

4. Sakisaka T, Takai Y. Biology and pathology of nectins and nectin-like molecules. Curr Opin Cell Biol 2004;16(5):513-21.

5. Takai $Y$, Nakanishi $H$. Nectin and afadin: novel organizers of intercellular junctions. J Cell Sci 2003;116(1):17-27.

6. Irie K, Shimizu K, Sakisaka T, Ikeda W, Takai Y. Roles and modes of action of nectins in cell-cell adhesion. Semin Cell Dev Biol 2004;15(6):643-56.

7. Nakanishi H, Takai Y. Roles of nectins in cell adhesion, migration and polarization. Biol Chem 2004;385(10):885-92.

8. Reymond N, Fabre S, Lecocq E, Adelaide J, Dubreuil P, Lopez M. Nectin4/PRR4, a new afadin-associated member of the nectin family that trans-interacts with nectin1/PRR1 through $\mathrm{v}$ domain interaction. J Biol Chem 2001;276(46):43205-15.

9. Takano A, Ishikawa N, Nishino R, Masuda K, Yasui $\mathrm{W}$, Inai $\mathrm{K}$, et al. identification of nectin-4 oncoprotein as a diagnostic and therapeutic target for lung cancer. Cancer Res 2009;69(16):6694-703.

10. Fabre-Lafay S, Garrido-Urbani S, Reymond N, Goncalves A, Dubreuil P, Lopez M. Nectin-4, a new serological breast cancer marker, is a substrate for tumor necrosis factor-alpha-converting enzyme (TACE)/ ADAM-17. J Biol Chem 2005;280(20):19543-50.

11. Oshima T, Sato S, Kato J, Ito Y, Watanabe T, Tsuji I, et al. Nectin-2 is a potential target for antibody therapy of breast and ovarian cancers. Mol Cancer 2013;12:60.

12. Fabre-Lafay S, Monville F, Garrido-Urbani S, Berruyer-Pouyet C, Ginestier C, Reymond N, et al. Nectin-4 is a new histological and serological tumor associated marker for breast cancer. BMC Cancer 2007;7:73.

13. Kanzaki N, Ogita H, Komura H, Ozaki M, Sakamoto $\mathrm{Y}$, Majima $\mathrm{T}$, et al. Involvement of the nectin-afadin complex in pdgf-induced cell survival. J Cell Sci 2008;121(12):2008-17.

14. Ikeda W, Nakanishi H, Miyoshi J, Mandai K, Ishizaki
$\mathrm{H}$, Tanaka M, et al. Afadin: a key molecule essential for structural organization of cell-cell junctions of polarized epithelia during embryogenesis. J Cell Biol 1999;146(5):1117-32.

15. Noyce RS, Bondre DG, Ha MN, Lin LT, Sisson G, Tsao MS, et al. Tumor cell marker PVRL4 (Nectin 4) is an epithelial cell receptor for measles virus. PLoS Pathog 2011;7(8):e1002240.

16. Karabulut M, Gunaldi M, Alis H, Afsar CU, Karabulut S, Serilmez M, et al. Serum nectin-2 levels are diagnostic and prognostic in patients with colorectal carcinoma. Clin Transl Oncol 2016;18(2):160-71.

17. Liang S, Yang Z, Li D, Miao X, Yang L, Zou Q, et al. The clinical and pathological significance of nectin-2 and DDX3 expression in pancreatic ductal adenocarcinomas. Dis Markers 2015;2015:379568.

18. Miao X, Yang ZL, Xiong L, Zou Q, Yuan Y, Li J, et al. Nectin-2 and DDX3 are biomarkers for metastasis and poor prognosis of squamous cell/adenosquamous carcinomas and adenocarcinoma of gallbladder. Int J Clin Exp Pathol 2013;6(2):179-90.

19. Li M, Qiao D, Pu J, Wang W, Zhu W, Liu H. Elevated Nectin-2 expression is involved in esophageal squamous cell carcinoma by promoting cell migration and invasion. Oncol Lett 2018;15(4):4731-6.

20. Erturk K, Karaman S, Dagoglu N, Serilmez M, Duranyildiz D, Tas F. Serum Nectin-2 and Nectin-4 are diagnostic in lung cancer: which is superior? Wien Klin Wochenschr 2019;131(17-18):419-26.

21. Deuss FA, Gully BS, Rossjohn J, Berry R. Recognition of Nectin-2 by the natural killer cell receptor T cell immunoglobulin and ITIM domain (TIGIT). J Biol Chem 2017;292(27):11413-22.

22. Lattanzio R, Ghasemi R, Brancati F, Sorda RL, Tinari N, Perracchio L, et al. Membranous Nectin-4 expression is a risk factor for distant relapse of T1-T2, N0 luminal-a early breast cancer. Oncogenesis 2014;3(9):e118.

23. Derycke MS, Pambuccian SE, Gilks CB, Kalloger SE, Ghidouche A, Lopez M, et al. Nectin 4 overexpression in ovarian cancer tissues and serum: potential role as a serum biomarker. Am J Clin Pathol 2010;134(5):835-45. 